Article

\title{
Size Control of Magnetite Nanoparticles in Excess Ligands as a Function of Reaction Temperature and Time
}

\author{
Masafumi Nakaya $^{1, *}$, Ryo Nishida ${ }^{2}$ and Atsushi Muramatsu ${ }^{1}$ \\ 1 Institute of Multidisciplinary Research for Advanced Materials, Tohoku University, \\ Sendai 980-8577, Japan; E-Mail: mura@tagen.tohoku.ac.jp \\ 2 School of Engineering, Tohoku University, Sendai 980-8579, Japan; \\ E-Mail: ryo-24d@mail.tagen.tohoku.ac.jp \\ * Author to whom correspondence should be addressed; E-Mail: m-nakaya@tagen.tohoku.ac.jp; \\ Tel.: +81-22-217-5164; Fax: +81-22-217-5165.
}

Received: 31 May 2014; in revised form: 7 July 2014 / Accepted: 22 July 2014 /

Published: 4 August 2014

\begin{abstract}
The novel synthesis of monodisperse magnetite $\mathrm{Fe}_{3} \mathrm{O}_{4}$ nanoparticles of varying sizes using a solventless synthetic method was developed. Iron salt was treated in excess oleylamine and oleic acid as ligands. The effect of the reaction temperature and time on the particle size was investigated and the particle sizes were easily tuned from 5.3 to $20.4 \mathrm{~nm}$ by changing the reaction temperature and time.
\end{abstract}

Keywords: $\mathrm{Fe}_{3} \mathrm{O}_{4}$ nanoparticle; solventless synthesis; size control

\section{Introduction}

Chemically synthesized superparamagnetic magnetite $\left(\mathrm{Fe}_{3} \mathrm{O}_{4}\right)$ nanoparticles have many attractive features, including their ease of synthesis, narrow size distribution, chemical stability, and high dispersibility in various solvents [1-8]. In addition, $\mathrm{Fe}_{3} \mathrm{O}_{4}$ nanoparticles exhibit high biocompatibility [9-12]. Therefore, they have potential uses in the biomedical field, including as contrast agents for magnetic resonance imaging (MRI) [13-18], drug delivery systems [19-21], and hyperthermia agents [22-24]. In order for that potential to come to fruition, size control is crucial because their magnetic properties strongly depend on size. In general, ferri- and ferromagnetic properties appear in particles larger than $30 \mathrm{~nm}$ [6]. However, particles smaller than $30 \mathrm{~nm}$ are desired in the biomedical field to facilitate superparamagnetism. In addition, even in particles smaller than 
$30 \mathrm{~nm}$, the magnetic properties strongly depend on the size [8,24]. Therefore, controlling the size of $\mathrm{Fe}_{3} \mathrm{O}_{4}$ nanoparticles is imperative in controlling the properties for various applications in the biomedical field.

In conventional synthetic procedures utilized to obtain superparamagnetic $\mathrm{Fe}_{3} \mathrm{O}_{4}$ nanoparticles with tunable sizes, seed-mediated growth is a very simple way to promote growth $[3,4]$. However, seed-mediated growth tends to broaden the size distribution because of a generation of nucleation in each step of the growth reaction. Hyeon et al. reported a synthetic method to control the size of iron oxide nanoparticles by changing the reaction temperature. The procedure can easily control the size of the nanoparticles and prepare the particles in large quantities, however, the crystal structure changed with the reaction temperature [7]. In order to control the crystal structure, it is better that the reaction be carried out under mild condition [25-28].

As one of the methods to prepare nanoparticles under mild conditions, we have examined the effect of complexation between metal ions and ligands [29,30]. Complexation is effective for suppressing nucleation and supplying metal ions slowly to growth. In order to form the complex efficiently, the metal salts are preferably dissolved and reacted in an excess amount of ligands without using conventional solvents, such as 1-octadecene, di-n-octylether, and benzyl ether. When using such organic solvents, the ratio of ligands to metal is low to form complexes efficiently. Here, we report a novel synthetic procedure for preparing $\mathrm{Fe}_{3} \mathrm{O}_{4}$ nanoparticles of various sizes by using a solventless synthesis, where oleylamine and oleic acid were used as ligands. In order to control particle sizes, the effect of reaction temperature and time was investigated.

\section{Results and Discussion}

The relationship between the reaction conditions and particle sizes of the resulting nanoparticles is summarized in Table 1.

Table 1. Summary of the relationship between the reaction conditions and the particle sizes of the resulting nanoparticles.

\begin{tabular}{llll}
\hline \multirow{2}{*}{ Reaction temperature $\left({ }^{\circ} \mathbf{C}\right)$} & \multicolumn{3}{l}{ Reaction time (h) } \\
\cline { 2 - 4 } & $\mathbf{1}$ & $\mathbf{3}$ & $\mathbf{6}$ \\
\hline 200 & & $5.3 \pm 0.6 \mathrm{~nm}$ & \\
250 & & $8.2 \pm 0.6 \mathrm{~nm}$ & \\
280 & $6.6 \pm 1.0 \mathrm{~nm}$ & $13.0 \pm 0.9 \mathrm{~nm}$ & $19.5 \pm 1.7 \mathrm{~nm}$ \\
300 & & $20.4 \pm 2.2 \mathrm{~nm}$ & \\
\hline
\end{tabular}

In order to understand the effect of reaction temperature on particle size, we obtained transmission electron microscope (TEM) images of the as-synthesized nanoparticles. The relationship between the reaction conditions and particle sizes of the resulting nanoparticles is summarized in Table 1. Figure 1 shows the TEM images of the nanoparticles as a function of reaction temperature. When the reaction temperature was $200{ }^{\circ} \mathrm{C}$, the resulting nanoparticles exhibited spherical shapes with a particle size of $5.3 \pm 0.6 \mathrm{~nm}$, notably the minimum size observed in this study (Figure 1a). When the reaction temperature was increased to $250{ }^{\circ} \mathrm{C}, 280{ }^{\circ} \mathrm{C}$, and $300{ }^{\circ} \mathrm{C}$, the size of the spherical particles increased to $8.2 \pm 0.6 \mathrm{~nm}, 13.0 \pm 0.9 \mathrm{~nm}$, and $20.4 \pm 2.2 \mathrm{~nm}$, respectively (Figure $1 \mathrm{~b}-\mathrm{d}$ ). The particle size tended 
to increase with increased reaction temperatures. In our previous study, the iron ions in an excess amount of ligands formed complexes with oleylamine and oleic acid [29]. Through stable complex formation, nucleation was suppressed. In order to promote the decomposition of the stable iron complex, a higher reaction temperature was required. When 1,2-hexadecanediol was not added into the reaction solution, larger Wüstite phase particles were obtained [30]. 1,2-Hexadecanediol worked to suppress the growth of the particles larger than $20 \mathrm{~nm}$ by promotion of the nucleation number.

Figure 1. TEM images of (a) $5.3 \pm 0.6 \mathrm{~nm}\left(200{ }^{\circ} \mathrm{C}\right)$; (b) $8.2 \pm 0.6 \mathrm{~nm}\left(250{ }^{\circ} \mathrm{C}\right)$; (c) $13.0 \pm 0.9 \mathrm{~nm}\left(280{ }^{\circ} \mathrm{C}\right)$; and (d) $20.4 \pm 2.2 \mathrm{~nm}\left(300{ }^{\circ} \mathrm{C}\right) \mathrm{Fe}_{3} \mathrm{O}_{4}$ nanoparticles. (Scale bar: $50 \mathrm{~nm}$ ).

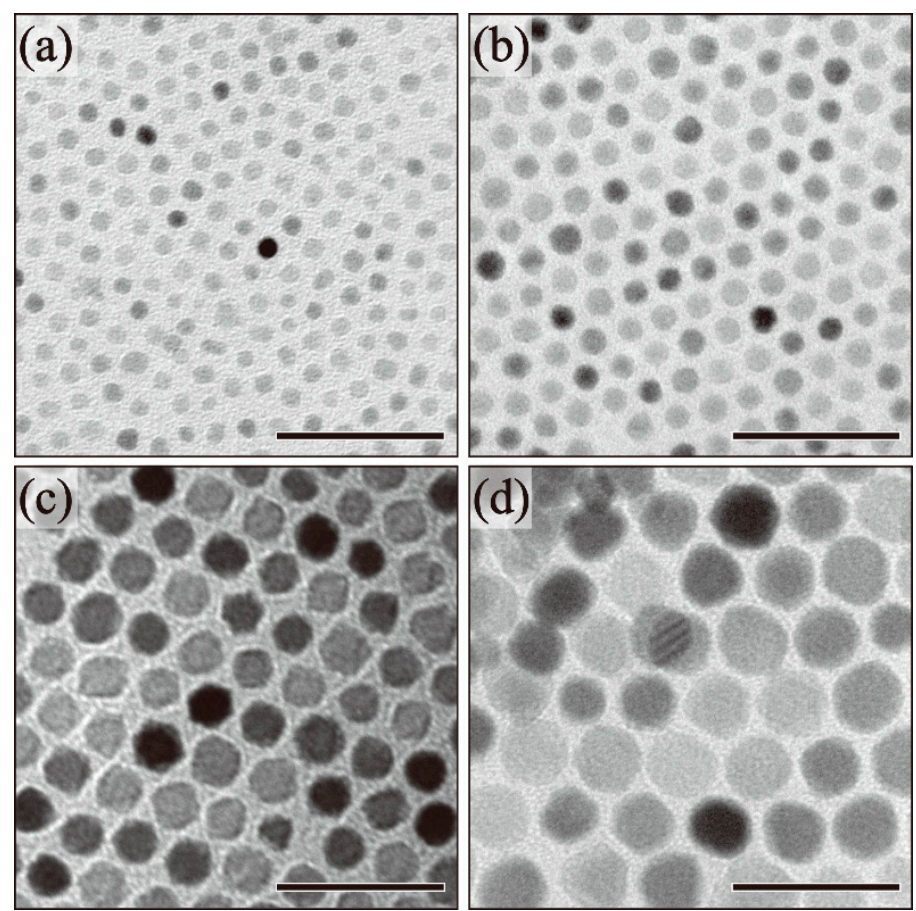

The crystal structures of the as-synthesized nanoparticles were determined by X-ray diffraction (XRD). Figure 2 shows the XRD patterns of the resulting nanoparticles as a function of reaction temperature. When the reaction temperature was $200{ }^{\circ} \mathrm{C}$, the observed peaks were small and broad (Figure 2a). Notably, $200{ }^{\circ} \mathrm{C}$ was too low of a temperature to improve the crystallinity, therefore, the peaks were not clear. However, when the reaction temperature was higher than $250{ }^{\circ} \mathrm{C}$, the patterns corresponding to the $\mathrm{Fe}_{3} \mathrm{O}_{4}$ phase could be observed clearly (Figure 2b-d). The peak width narrowed slightly because the crystallinity and particle size improved with increasing temperatures $[31,32]$. The differences in the XRD patterns between $\mathrm{Fe}_{3} \mathrm{O}_{4}$ and $\gamma-\mathrm{Fe}_{2} \mathrm{O}_{3}$ phases are small. In order to determine the structure of the $\mathrm{Fe}_{3} \mathrm{O}_{4}$ phase, the coexistence of $\mathrm{Fe}^{2+}$ and $\mathrm{Fe}^{3+}$ in the particles must be demonstrated. 
Figure 2. XRD patterns of (a) $5.3 \pm 0.6 \mathrm{~nm}\left(200{ }^{\circ} \mathrm{C}\right)$; (b) $8.2 \pm 0.6 \mathrm{~nm}\left(250{ }^{\circ} \mathrm{C}\right)$; (c) $13.0 \pm 0.9 \mathrm{~nm}\left(280^{\circ} \mathrm{C}\right)$; and (d) $20.4 \pm 2.2 \mathrm{~nm}\left(300^{\circ} \mathrm{C}\right) \mathrm{Fe}_{3} \mathrm{O}_{4}$ nanoparticles.

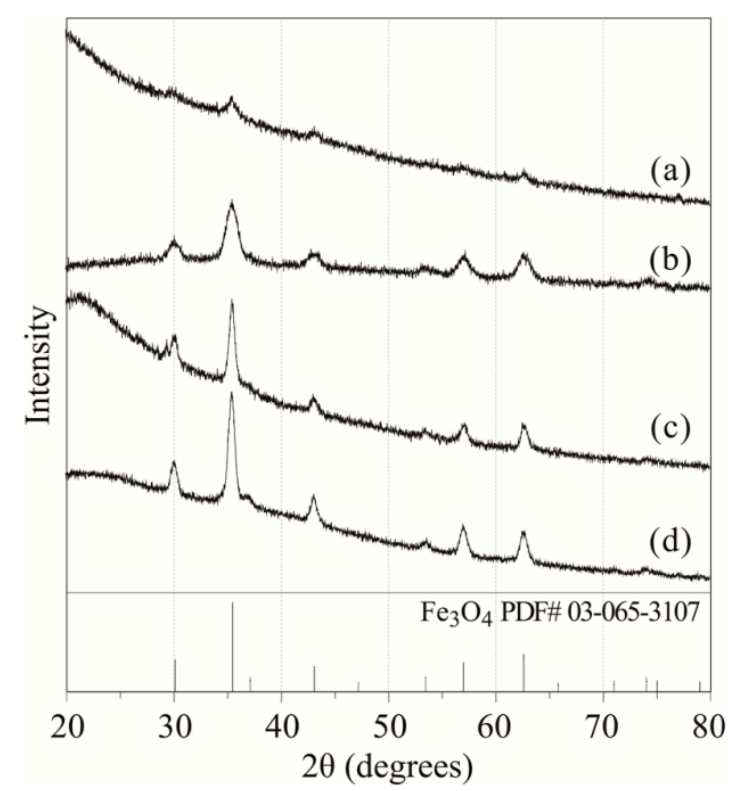

In order to determine the valence of iron in the nanoparticles, the near-infrared absorption of the nanoparticles was measured. Adjacent $\mathrm{Fe}^{2+}$ and $\mathrm{Fe}^{3+}$ ions in the phase lead to electron transitions assigned to intervalence charge transfer (IVCT) transitions in the near-infrared (NIR) region [33,34]. However, the $\mathrm{Fe}^{3+}$ transition in the UV-Vis yields essentially the same spectrum in the presence or absence of nearby $\mathrm{Fe}^{2+}$ [34]. Therefore, the absorption spectra in the Vis-NIR region from 600 to $1,400 \mathrm{~nm}$ were used. Figure 3 shows the Vis-NIR spectra of the resulting nanoparticles in $n$-hexane (concentration: $0.005 \mathrm{wt} \%$ ). The broad absorption in the NIR region demonstrated coexistence of $\mathrm{Fe}^{3+}$ and $\mathrm{Fe}^{2+}$ in the nanoparticles. These results support that the XRD patterns (Figure 2) shows magnetite, not maghemite.

Figure 3. Vis-NIR spectra of (a) $5.3 \pm 0.6 \mathrm{~nm}\left(200{ }^{\circ} \mathrm{C}\right)$; (b) $8.2 \pm 0.6 \mathrm{~nm}\left(250{ }^{\circ} \mathrm{C}\right)$; (c) $13.0 \pm 0.9 \mathrm{~nm}\left(280^{\circ} \mathrm{C}\right)$; and (d) $20.4 \pm 2.2 \mathrm{~nm}\left(300^{\circ} \mathrm{C}\right) \mathrm{Fe}_{3} \mathrm{O}_{4}$ nanoparticles.

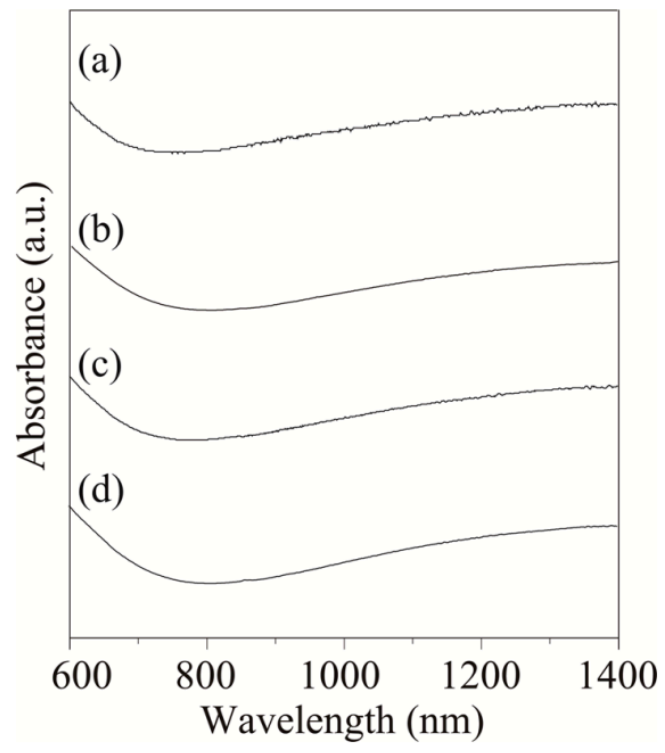


Next, we moved to an investigation of the effect of reaction time on particle size and structure. The relationship between the reaction conditions and particle sizes of the resulting nanoparticles is summarized in Table 1. Figure 4 shows the TEM images of the as-synthesized $\mathrm{Fe}_{3} \mathrm{O}_{4}$ nanoparticles as a function of reaction time. The reaction temperature was maintained at $280{ }^{\circ} \mathrm{C}$ for 1,3 , and $6 \mathrm{~h}$. The mean diameter of the nanoparticles was $6.6 \pm 1.0 \mathrm{~nm}, 13.0 \pm 0.9 \mathrm{~nm}$, and $19.5 \pm 1.7 \mathrm{~nm}$ after $1 \mathrm{~h}, 3 \mathrm{~h}$, and $6 \mathrm{~h}$, respectively. Longer reaction times led to increase particle growth with narrow size distribution. However, when the reaction time was longer than $6 \mathrm{~h}$, nanoparticles larger than $20 \mathrm{~nm}$ were not obtained.

Figure 4. TEM images of (a) $6.6 \pm 1.0 \mathrm{~nm}(1 \mathrm{~h})$; (b) $13.0 \pm 0.9 \mathrm{~nm}(3 \mathrm{~h})$; and (c) $19.5 \pm 1.7 \mathrm{~nm}(6 \mathrm{~h}) \mathrm{Fe}_{3} \mathrm{O}_{4}$ nanoparticles. (Scale bar: $50 \mathrm{~nm}$ ).
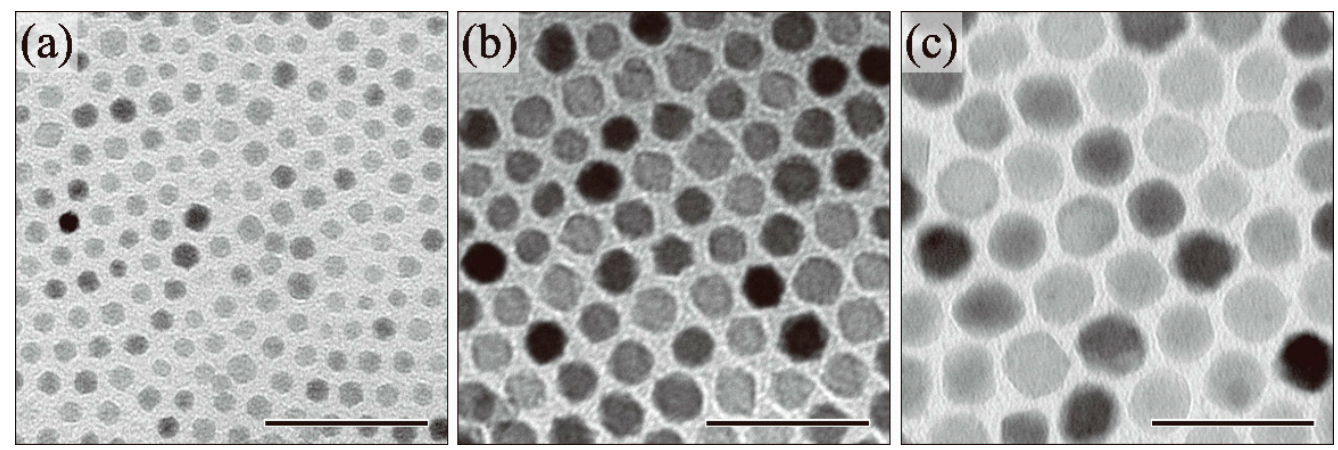

Figure 5 shows the XRD patterns of the $\mathrm{Fe}_{3} \mathrm{O}_{4}$ nanoparticles as a function of reaction time. The patterns corresponding to the $\mathrm{Fe}_{3} \mathrm{O}_{4}$ phase were clearly observed in all nanoparticles. A slight decrease in peak width was observed with extended reaction time. This phenomenon depended on the particle growth and corresponded well with the TEM results. In addition, the absorbance in the NIR region derived from $\mathrm{Fe}^{3+}-\mathrm{Fe}^{2+}$ IVCT was observed in all nanoparticles (Figure 6). As such, a portion of the $\mathrm{Fe}^{3+}$ ions were reduced to $\mathrm{Fe}^{2+}$ and the coexistence of $\mathrm{Fe}^{3+}$ and $\mathrm{Fe}^{2+}$ ions in the nanoparticles was maintained regardless of reaction time. The particle size increased and the $\mathrm{Fe}_{3} \mathrm{O}_{4}$ phase was maintained with longer reaction times.

Figure 5. XRD patterns of (a) $6.6 \pm 1.0 \mathrm{~nm}(1 \mathrm{~h})$; (b) $13.0 \pm 0.9 \mathrm{~nm}(3 \mathrm{~h})$; and (c) $19.5 \pm 1.7 \mathrm{~nm}(6 \mathrm{~h}) \mathrm{Fe}_{3} \mathrm{O}_{4}$ nanoparticles.

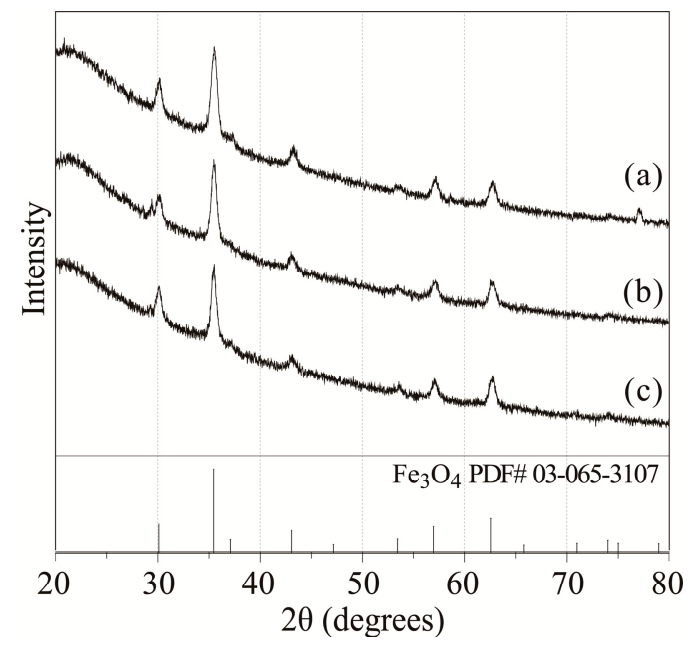


Figure 6. Vis-NIR spectra of (a) $6.6 \pm 1.0 \mathrm{~nm}(1 \mathrm{~h})$; (b) $13.0 \pm 0.9 \mathrm{~nm}(3 \mathrm{~h})$; and (c) $19.5 \pm 1.7 \mathrm{~nm}(6 \mathrm{~h}) \mathrm{Fe}_{3} \mathrm{O}_{4}$ nanoparticles.

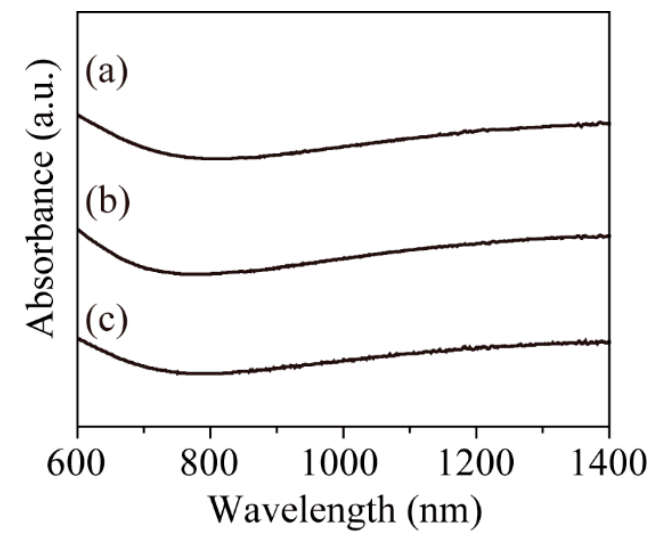

\section{Experimental Section}

\subsection{Apparatus and Reagents}

Iron(III) acetylacetonate was purchased from Kanto Chemical (Tokyo, Japan). 1,2-hexadecanediol and oleylamine (purity $>70 \%$ ) were purchased from Sigma-Aldrich (St. Louis, MO, USA). Oleic acid (purity $>85 \%$ ) was purchased from Tokyo Chemical Industry (Tokyo, Japan). All the reagents except oleylamine were used as received. Oleylamine was used after distillation under reduced pressure. The sizes and shapes of the resulting nanoparticles were observed by TEM (Hitachi H-7650, Tokyo, Japan, operated at $100 \mathrm{kV}$ ). The crystal structures were identified by XRD (Rigaku Ultima IV, Tokyo, Japan, operated at $40 \mathrm{kV}-40 \mathrm{~mA}, \mathrm{Cu}$ source). The nature of the Fe ions was determined by the absorbance in the Vis-NIR region of the sample using a Hitachi U-4100 instrument.

\subsection{Synthesis of $\mathrm{Fe}_{3} \mathrm{O}_{4}$ Nanoparticles}

$\mathrm{Fe}_{3} \mathrm{O}_{4}$ nanoparticles were prepared by the following synthetic procedure, which was based on our previous study [29]: the reaction was carried out in the $100 \mathrm{~mL}$ three-necked round-bottom flask equipped with a condenser and a thermometer. The heating was carried out by a heating mantle. Iron acetylacetonate (III) $(1 \mathrm{mmol})$ and 1,2-hexadecanediol $(3.0 \mathrm{mmol})$ as $\mathrm{Fe}^{3+}$ reducing agent were added into a mixture of oleic acid $(15 \mathrm{mmol})$ and distilled oleylamine $(15 \mathrm{mmol})$. The solution was maintained at $130{ }^{\circ} \mathrm{C}$ for $30 \mathrm{~min}$ with vigorous stirring under a reduced atmosphere (ca. $200 \mathrm{~Pa}$ ) for dissolution and removal of impurities such as water molecules and organic molecules with low boiling temperatures. In this phase, the solution color was dark brown. Then, the solution was heated to reaction temperatures of $200{ }^{\circ} \mathrm{C}, 250{ }^{\circ} \mathrm{C}, 280{ }^{\circ} \mathrm{C}$, and $300{ }^{\circ} \mathrm{C}$ for $1 \mathrm{~h}, 3 \mathrm{~h}$, and $6 \mathrm{~h}$ under a nitrogen atmosphere (1 atm.). The solution color changed to black. Finally, the solution was left to cool to room temperature by remove of the heat source. When the solution becomes hard or loses fluidity after cooling to room temperature, the resulting solidified solution was dissolved by adding $10 \mathrm{~mL} n$-hexane before the following precipitation process. The iron oxide nanoparticles were precipitated by the addition of ethanol $(70 \sim 80 \mathrm{~mL})$ and were subsequently subjected to centrifugation (3000 $\mathrm{g}, 10 \mathrm{~min})$. The precipitated nanoparticles were redispersed into $n$-hexane. 


\section{Conclusions}

In this study, the growth of $\mathrm{Fe}_{3} \mathrm{O}_{4}$ nanoparticles in excess ligands was investigated. An excess ratio of ligands to metal ions can suppress nucleation via complexation with iron ions and slowly promote particle growth. The particle sizes depended strongly on the reaction temperature due to its effect on the activity of the iron complexes, in addition to the reaction time due to the allowed growth time. By changing the reaction temperature and time, monodisperse $\mathrm{Fe}_{3} \mathrm{O}_{4}$ nanoparticles with tunable sizes from $5.3 \mathrm{~nm}$ to $20.4 \mathrm{~nm}$ were successfully prepared.

\section{Acknowledgments}

This work was supported in part by the JSPS KAKENHI Grant-in-Aid for young Scientists (B) (No.24750121, Masafumi Nakaya).

\section{Author Contributions}

MN designed research, performed research, analyzed the data and wrote the manuscript. RN performed research, analyzed the data and wrote the manuscript. AM helped to perform research and draft the manuscript. All authors read and approved the final manuscript.

\section{Conflicts of Interest}

The authors declare no conflict of interest.

\section{References}

1. Rockenberger, J.; Scher, E.C.; Alivisatos, A.P. A new nonhydrolytic single-precursor approach to surfactant-capped nanocrystals of transition metal oxides. J. Am. Chem. Soc. 1999, 121, 11595-11596.

2. Hyeon, T. Chemical synthesis of magnetic nanoparticles. Chem. Commun. 2003, 8, 927-934.

3. Sun, S.; Zeng, H. Size-Controlled Synthesis of Magnetite Nanoparticles. J. Am. Chem. Soc. 2002, 124, 8204-8205.

4. Sun, S.; Zeng, H.; Robinson, D.B.; Raoux, S.; Rice, P.M.; Wang, S.X.; Li, G. Monodisperse $\mathrm{MFe}_{2} \mathrm{O}_{4}(\mathrm{M}=\mathrm{Fe}, \mathrm{Co}, \mathrm{Mn})$ nanoparticles. J. Am. Chem. Soc. 2004, 126, 273-279.

5. Casula, M.F.; Jun, Y.-W.; Zaziski, D.J.; Chan, E.M.; Corrias, A.; Alivisatos, A.P. The concept of delayed nucleation in nanocrystal growth demonstrated for the case of iron oxide nanodisks. J. Am. Chem. Soc. 2006, 128, 1675-1682.

6. Kim, D.; Lee, N.; Park, M.; Kim, B.H.; An, K.; Hyeon, T. Synthesis of uniform ferrimagnetic magnetite nanocubes. J. Am. Chem. Soc. 2009, 131, 454-455.

7. Park, J.; An, K.; Hwang, Y.; Park, J.-G.; Noh, H.-J.; Kim, J.-Y.; Park, J.-H.; Hwang, N.-M.; Hyeon, T. Ultra-large-scale syntheses of monodisperse nanocrystals. Nat. Mater. 2004, 3, $891-895$. 
8. Lee, N.; Choi, Y.; Lee, Y.; Park, M.; Moon, W.K.; Choi, S.H.; Hyeon, T. Water-dispersible ferrimagnetic iron oxide nanocubes with extremely high $r_{2}$ relaxivity for highly sensitive in vivo MRI of tumors. Nano Lett. 2012, 12, 3127-3131.

9. Lu, A.-H.; Salabas, E.L.; Schüth, F. Magnetic nanoparticles: Synthesis, protection, functionalization, and application. Angew. Chem. Int. Ed. 2007, 46, 1222-1244.

10. Huber, D.L. Synthesis, properties, and applications of iron nanoparticles. Small 2005, 1, 482-501.

11. Bulte, J.W.; Kraitchman, D.L. Iron oxide MR contrast agents for molecular and cellular imaging. NMR Biomed. 2004, 17, 484-499.

12. Jun, Y.-W.; Lee, J.-H.; Cheon, J. Chemical design of nanoparticle probes for high-performance magnetic resonance imaging. Angew. Chem. Int. Ed. 2008, 47, 5122-5135.

13. Na, H.B.; Song, I.C.; Hyeon, T. Inorganic nanoparticles for MRI contrast agents. Adv. Mater. 2009, 21, 2133-2148.

14. Xie, J.; Liu, G.; Eden, H.S.; Ai, H.; Chen, X. Surface-engineered magnetic nanoparticle platforms for cancer imaging and therapy. Acc. Chem. Res. 2011, 44, 883-892.

15. Srinvivas, M.; Armtzen, E.H.J.G.; Bulte, J.W.M.; Heerschap, A.; de Vries, I.J.M.; Figdor, C.G. Imaging of cellular therapies. Adv. Drug Deliv. Rev. 2010, 62, 1080-1093.

16. Lee, N.; Hyeon, T. Designed synthesis of uniformly sized iron oxide nanoparticles for efficient magnetic resonance imaging contrast agents. Chem. Soc. Rev. 2012, 41, 2575-2589.

17. Cheng, K.; Peng, S.; Xu, C.; Sun, S. Porous hollow $\mathrm{Fe}_{3} \mathrm{O}_{4}$ nanoparticles for targeted delivery and controlled release of cisplatin. J. Am. Chem. Soc. 2009, 131, 10637-10644.

18. Piao, Y.; Kim, J.; Na, H.B.; Kim, D.; Baek, J.S.; Ko, M.K.; Lee, J.H.; Shokouhimehr, M.; Hyeon, T. Wrap-bake-peel process for nanostructural transformation from $\beta$-FeOOH nanorods to biocompatible iron oxide nanocapsules. Nat. Mater. 2008, 7, 242-247.

19. Wang, B.; Xu, C.; Xie, J.; Yang, Z.; Sun, S. pH controlled release of chromone from chromone-Fe $\mathrm{O}_{4}$ nanoparticles. J. Am. Chem. Soc. 2008, 130, 14436-14437.

20. Lee, J.-H.; Jang, J.-T.; Choi, J.-S.; Moon, S.H.; Noh, S.-H.; Kim, J.-W.; Kim, J.-G.; Kim, I.-S.; Park, K.I.; Cheon, J. Exchange-coupled magnetic nanoparticles for efficient heat induction. Nat. Nanotech. 2011, 6, 418-422.

21. Fortin, J.-P.; Wilhelm, J.-P.C.; Servais, J.; Ménager, C.; Bacri, J.-C.; Gazeau, F. Size-sorted anionic iron oxide nanomagnets as colloidal mediators for magnetic hyperthermia. J. Am. Chem. Soc. 2007, 129, 2628-2635.

22. Hao, R.; Xing, R.; Xu, Z.; Hou, Y.; Gao, S.; Sun, S. Synthesis, Functionalization, and biomedical applications of multifunctional magnetic nanoparticles. Adv. Mater. 2010, 22, 2729-2742.

23. Gao, J.; Gu, H.; Xu, B. Multifunctional magnetic nanoparticles: Design, synthesis, and biomedical applications. Acc. Chem. Res. 2009, 42, 1097-1107.

24. Khandhar, A.P.; Ferguson, R.M.; Krishnan, K.M. Monodispersed magnetite nanoparticles optimized for magnetic fluid hyperthermia: Implications in biological systems. J. Appl. Phys. 2011, 109, 07B310.

25. Xu, R.; Wang, Y.; Jia, G.; Xu, W.; Liang, S.; Yin, D. Zinc blende and wurtzite cadmium sulfide nanocrystals with strong photoluminescence and ultrastability. J. Cryst. Growth 2007, 299, 28-33. 
26. Silva, L.A.; Ryu, S.Y.; Choi, J.; Choi, W.; Hoffmann, M.R. Photocatalytic hydrogen production with visible light over Pt-interlinked hybrid composites of cubic-phase and hexagonal-phase CdS. J. Phys. Chem. C 2008, 112, 12069-12073.

27. Kanehara, M.; Arakawa, H.; Honda, T.; Saruyama, M.; Teranishi, T. Large-scale synthesis of high-quality metal sulfide semiconductor quantum dots with tunable surface-plasmon resonance frequencies. Chem. Eur. J. 2012, 18, 9230-9238.

28. Nakaya, M.; Tanaka, I.; Muramatsu, A. Preparation of manganese doped cadmium sulfide nanoparticles in zincblende phase and their magnetic properties. J. Nanosci. Nanotechnol. 2012, 12, 9003-9006.

29. Nakaya, M.; Kanehara, M.; Teranishi, T. One-pot synthesis of large FePt nanoparticles from metal salts and their thermal stability. Langmuir 2006, 22, 3485-3487.

30. Nakaya, M.; Nishida, R.; Muramatsu, A. Preparation of wüstite nanoparticles by a solventless synthetic procedure. Chem. Lett. 2013, 42, 863-865.

31. Murray, C.B.; Kagan, C.R.; Bawendi, M.G. Synthesis and characterization of monodisperse nanocrystals and close-packed nanocrystals assemblies. Annu. Rev. Mater. Sci. 2000, 30, 545-610.

32. Shevchenko, E.V.; Talapin, D.V.; Schnablegger, H.; Konorwski, A.; Festin, Ö.; Svedlindh, P.; Haase, M.; Weller, H. Study of nucleation and growth in the organometallic synthesis of magnetic alloy nanocrystals: The role of nucleation rate in size control of $\mathrm{CoPt}_{3}$ nanocrystals. J. Am. Chem. Soc. 2003, 125, 9090-9101.

33. Fontijn, W.F.J.; van der Zaag, P.J.; Devillers, M.A.C.; Brabers, V.A.M.; Metselaar, R. Optical and magneto-optical polar Kerr spectra of $\mathrm{Fe}_{3} \mathrm{O}_{4}$ and $\mathrm{Mg}^{2+}$ - or $\mathrm{Al}^{3+}$-substituted $\mathrm{Fe}_{3} \mathrm{O}_{4}$. Phys. Rev. B 1997, 56, 5432-5442.

34. Tang, J.; Myers, M.; Bosnick, K.A.; Brus, L.E. Magnetite $\mathrm{Fe}_{3} \mathrm{O}_{4}$ nanocrystals: Spectroscopic observation of aqueous oxidation kinetics. J. Phys. Chem. B 2003, 107, 7501-7506.

Sample Availability: Samples of the magnetite nanoparticles are available from the authors.

(C) 2014 by the authors; licensee MDPI, Basel, Switzerland. This article is an open access article distributed under the terms and conditions of the Creative Commons Attribution license (http://creativecommons.org/licenses/by/3.0/). 